\title{
Los ejemplos en las dos primeras gramáticas de español para italianos
}

Algunas consideraciones sobre las fuentes literarias

\section{Luisa Chierichetti}

\section{OpenEdition}

\section{Journals}

Edición electrónica

URL: https://journals.openedition.org/cher/8880

DOI: $10.4000 /$ cher.8880

ISSN: 2803-5992

\section{Editor}

Presses universitaires de Strasbourg

\section{Edición impresa}

Fecha de publicación: 1 diciembre 2010

Paginación: 47-62

ISBN: 978-2-35410-029-2

ISSN: 1968-035X

\section{Referencia electrónica}

Luisa Chierichetti, «Los ejemplos en las dos primeras gramáticas de español para italianos », reCHERches [En línea], 5 | 2010, Publicado el 17 diciembre 2021, consultado el 25 enero 2022. URL: http://journals.openedition.org/cher/8880 ; DOI: https://doi.org/10.4000/cher.8880

\section{(c) (1) (9)}

Ce(tte) œuvre est mise à disposition selon les termes de la Licence Creative Commons Attribution -

Pas d'Utilisation Commerciale - Partage dans les Mêmes Conditions 4.0 International. 


\title{
Los ejemplos en las dos primeras gramáticas de español para italianos: algunas consideraciones sobre las fuentes literarias
}

\author{
LUISA CHIERICHETTI \\ Università degli Studi di Bergamo
}

\begin{abstract}
$\mathrm{Z}^{\mathrm{n}}$ este trabajo se ofrece una aproximación al aparato ejemplar de dos Cobras destinadas al estudio de la lengua española que aparecen en Italia durante la segunda mitad del siglo Xvi: Il paragone della lingua toscana et castigliana de Giovanni Mario Alessandri (1560) y las Osservationi della lingua castigliana de Giovanni Miranda (1566) ${ }^{1}$, focalizando la atención en la manera de tratar los ejemplos de origen literario.
\end{abstract}

La creación y difusión de las obras para el aprendizaje del castellano es especialmente significativa en el territorio italiano en la época que va de la paz de Cateau Cambrésis (1559), cuando Felipe II abandona Bruselas, hasta la Guerra de Sucesión española. El acercamiento producido entre el mundo intelectual italiano y el español, palpable ya desde los primeros años del reinado de los Reyes Católicos (Croce 1971: 105), se hace más estrecho durante el reinado de Carlos V, cuando intelectuales como el Galateo y Castiglione ven necesario que el cortesano conozca la lengua castellana, todo esto sin olvidar que en Italia residen personalidades como Juan Boscán, Cristóbal de Castillejo, Miguel de Cervantes, Garcilaso de la Vega, Antonio de Guevara, Diego Hurtado de Mendoza, Juan de Valdés... El libro literario español está ampliamente difundido, y en el más importante centro editorial de Europa, Venecia, se traducen libros de caballerías, obras históricas,

1 Para esta contribución me baso en un artículo que publiqué durante mis estudios doctorales (Chierichetti 1997). 
cancioneros, novelas sentimentales y obras tales como La lozana andaluza y La Celestina (Meregalli 1974: 12-19). A la publicación de textos para la enseñanza de la lengua española contribuyen sobre todo Nápoles (véase el estudio fundamental de Croce 1949) y el Ducado de Urbino, que tuvo gran importancia por sus relaciones con España en el ámbito social y literario y, en gran parte, político-económico (García Dini 1995: 11-12).

Los primeros instrumentos utilizados por los extranjeros para aprender el español fueron algunas obras que estaban destinadas a la enseñanza del latín, como el Universal vocabulario en latín y romance de Alfonso Fernández de Palencia (1490) o el Diccionario latino-español (1492) y el Vocabulario Español-Latino (1495) de Nebrija. Del Vocabularium ex latino sermone in Siciliensem et hispaniensem denuo traductum (1520) de Lucio Cristofaro Scobar, traducción al siciliano del diccionario latino-español de Nebrija, tenemos una edición veneciana de 1519-20; las voces latinas, sicilianas y castellanas están dispuestas en tres columnas, pero sólo las dos primeras están ordenadas alfabéticamente. También seguía vigente la tradición latina de los manuales bilingües parecidos a los modernos manuales de conversación, que se publicaban con un diccionario ordenado primeramente por orden alfabético y luego clasificado en capítula según un criterio semántico. Los glosarios ordenados por áreas semánticas, que contienen el léxico utilizado en un diálogo o un texto narrativo, resultaban de mayor utilidad e independencia. Alfonso de Ulloa escribió un « dizionarietto » para la edición del Orlando Furioso en la traducción al castellano de Urrea, y añadió a la Celestina una "espositione da lui fatta nella [lingua] italiana, di parecchi vocaboli hispanioli difficili contenuti quasi tutti nella Tragicomedia» (Mele 1914: 14). Ulloa colaboró con la familia de editores venecianos Giolito, preparando algunas brevísimas reglas de pronunciación para la Cárcel de amor, la Celestina y las obras de Boscán.

Alda Croce señala que el primer rudimento de gramática española son las reglas para entender el castellano que el editor Stefano da Sabbio anteponía a los libros que publicaba en Venecia (Croce 1971: 121), pero la primera gramática para italohablantes es II paragone della lingua toscana et castigliana, que tuvo una única edición, publicada por Giovanni Mario Alessandri en Nápoles en $1560^{2}$. El autor, un italiano nacido en Urbino,

2 García Dini (1995: 11) afirma que este instrumento para la enseñanza nació por una exigencia de tipo religioso cuyo objetivo estaba íntimamente relacionado con los valdesianos. Bertini, basándose en la licencia, concedida por el vicario de la Archidiócesis de Nápoles, el 7 de junio de 1559, fecha la composición en 1558 o en los primeros meses de 1559 (Bertini 1953: 30). 
había residido en España en el entorno de la Corte y allí aprendió el español "copioso, leggiadro e di molta autorità ", ya no solo por el uso, sino también por el estudio ( «non solo per uso como sogliono quasi tutti i forestieri [...] ma ancora per lunga lettione et osservationi certissime». Al parecer se trataba de una persona muy bien relacionada con importantes familias (Esteba Ramos 2005: 42); por su parte, el padre del ibero-americanismo italiano, Giovanni Maria Bertini, baraja la hipótesis de que tal vez fuera preceptor del duque de Montalto y obispo en Oppido, Mileto y luego en San Marco en Calabria; "dotto in entrambe le leggi, autore [...][anche] di un trattato sovra la musica» (Bertini 1956: 28-29).

Las Osservationi della lingua castigliana di M. Giovanni Miranda divise in quatro libri: ne' quali s'insegna con gran facilità la perfetta lingua Spagnuola. Con due tavole: l'una de'capi essentiali, et l'altra delle cose notabili se publicaron en Venecia de mano de Giovanni Giolito. El volumen tuvo gran fortuna editorial: se hicieron dos ediciones (1566 y 1583), la primera con tres reediciones $(1567,1568$ y 1569) y la segunda con cinco $(1584,1585$, 1594, 1595 y 1622) (Carreras 2002: 19); de la obra se hizo una versión dialogada y unos compendios, y en ella se basaron Oudin y Franciosini para sus afortunadísimas obras. El español Juan Miranda, afincado en Italia, vivió en Venecia al menos desde 1562 - año de publicación de una traducción de Miranda de una novela de caballerías - si no fue desde 1552. Según Carreras (1993) Miranda fue un hombre muy culto, con grandes conocimientos de gramática y de literatura, que seguramente llegó a Italia con el séquito de algún embajador, como intérprete o tal vez como espía, y en la Corte veneciana supo relacionarse con las más ilustres personalidades.

Las obras de Alessandri y Miranda se sitúan en la confluencia entre dos maneras de entender la gramática de la lengua vulgar, la de Nebrija y la de Valdés. En su origen encontramos la voluntad claramente expresada por Nebrija de dar dignidad al castellano utilizando los criterios aplicados al latín ${ }^{3}$,

3 Nebrija, en el prólogo a su Gramática de la lengua castellana, aclara los tres propósitos principales de su trabajo: "reduzir en artificio este nuestro lenguaje castellano, para que lo que agora et de aquí adelante en él se escriviere pueda quedar en un tenor, et estender se en toda la duración de los tiempos que están por venir, como vemos que se ha hecho en la lengua griega et latina, las cuales por aver estado debaxo de arte, aun que sobre ellas an pasado muchos siglos, toda via queda en una uniformidad " (Nebrija 1989: 112-113); " ayudar a los ombres de nuestra lengua que querrán estudiar la gramática del latín " (Nebrija 1989: 113); exaltar la lengua castellana a través del clásico topos de la «lengua compañera del imperio » (Nebrija 1989: 109), porque " los pueblos bárbaros et las naciones de peregrinas lenguas [...] [tienen] necessidad de recebir las leies quel vencedor pone al vencido, et con ellas nuestra lengua » (Nebrija 1989: 113). 
pero, sobre todo en las Osservationi, se reconoce en la atención al uso lingüístico de toscano y castellano y, en la sistemática comparación entre los dos idiomas, la intención valdesiana de escribir una gramática del castellano que no sea simple adaptación de la latina, sino que se base en el uso común de hablar, ejemplificado por los refranes "nacidos en el vulgo" (Valdés 1982: 48). El Paragone y las Osservationi son dos textos producidos estructuralmente en forma de libro y destinados al uso inmediato de circuitos sociales y culturales (Quondam 1978: 288) que se identifican con las clases en estrecho contacto con la Corte de España y con los españoles residentes, o de visita, en los estados italianos. Son textos de consumo, instrumentos «útiles» nacidos en el proceso de extensión de la alfabetización (Quondam 1978: 285) y al lado del debate que fundó la disciplina lingüística de las lenguas vulgares en la Europa moderna4.

Los manuales para la enseñanza de la lengua extranjera pueden considerarse como textos expositivos cuya función específica es la explicativoargumentativa, basada en la intención de explicar a quien no sabe (Sabatini 1990 : 695). Desde un punto de vista estructural se distingue un «marco », un conjunto de elementos que atañe a las situaciones pragmáticas en las que se desarrolla la argumentación (Lo Cascio 1991: 57); un núcleo fundamental, que incluye la descripción metalingüística y la explicación gramatical; un «aparato ejemplar», que consiste en una serie de muestras de la lengua meta, y eventualmente, y con finalidad contrastiva, también de la lengua materna. En el marco y en el núcleo fundamental se perfila la voz del autor que presenta su trabajo definiéndolo en función del lector modelo. Esta voz se presenta en las explicaciones gramaticales y también en el aparato paratextual en donde se especifica el grupo de usuarios y, por lo tanto, la comunidad lingüística a la que se dirige la obra ${ }^{5}$; de ahí que, coherentemente, en el Paragone y las Osservationi la voz del autor se exprese en italiano.

Considero como «ejemplo» en un texto gramatical «todo objeto lingüístico, cualquiera que sea su estructura, derivado de la lengua objeto:

4 Entre los primeros textos gramaticales de lengua vulgar italiana para uso práctico hay que nombrar la Grammatica volgare de M. Ateneo Carlino (Nápoles, 1533), las Annotazioni della volgar lingua de Alberto Accarigi (Venecia, 1537), la Grammatica volgare trovata nelle opere di Petrarca, Boccaccio, Cin da Pistoia, Guitton d'Arezzo de Libero Gaetano Tizzone di Pofi (Nápoles, 1538) y dos obras también citadas por Miranda: los Fondamenti del parlar toscano, de Rinaldo Corso (Venecia, 1549) y las Osservazioni nella lingua volgare divise in quattro libri, di Lodovico Dolce (Venecia, 1550).

5 En las gramáticas antiguas, como las de Alessandri y Miranda, forman parte del aparato paratextual también las dedicatorias, de las que además pueden extraerse importantes datos biográficos de los autores. 
todo fragmento de la lengua objeto insertado en el discurso gramatical» (Chevillard et al. 2007: 6; la traducción es mía). Los ejemplos suelen presentarse de manera autónoma en las gramáticas, con demarcaciones tipográficas, o bien con unas herramientas propiamente lingüísticas (Chevillard et al. 2007: 9-14). A la simulación comunicativa introducida con los ejemplos puede aplicársele la distinción entre autor y animador que Goffman (1987: 175-210) reconoce en el paradigma conversacional. En el apartado de los ejemplos se identifica, pues, junto a la explicación gramatical del autor, la segunda voz de un "animador» de representaciones de acontecimientos comunicativos que reformulan, en una situación de uso plausible y recurrente, palabras ajenas y discursos repetidos o discursos reproducidos. Las fuentes pueden ser orales o escritas, las muestras pueden extraerse de documentos intrascendentes, o bien de obras de referencia, pueden reelaborarse y adaptarse para finalidades metalingüísticas. Se trata, en cualquier caso, de textos "tra-ducidos», reproducidos y encajados en el texto por el animador: son palabras «ya habitadas» que el discente recibe y hace suyas.

En Il paragone della lingua toscana et castigliana la recopilación de ejemplos y de reglas gramaticales, como ya anotaba Bertini (1956: 30-31) tiene carácter empírico, se basa en una observación directa de la lengua, escrita y oral, y se sitúa en el plano de la comunicación lingüística práctica. A menudo las observaciones referidas a la oralidad están introducidas por expresiones explícitamente atribuibles a la experiencia directa del autor y a las fuentes utilizadas:

Ma per che ne' sopradetti essempi non s'è posta la, ç, con la zeriglia se no dinanzi alle vocali, a, o, u, s'ha da notare che la, c, posta dinanzi alle vocali, $\mathrm{e}$, et $\mathrm{i}, \mathrm{o}$ c'habbia di sotto la zeriglia o nò sempre si pronuntia come s'è detto della ç con la zeriglia, et per quanto io vedo nelle buone impressioni, mi pare che dinanzi a queste lettere, e, et, i, non si soglia porre sotto la, c, zeriglia alcuna, ne io ve la pongo mai come cosa non necessaria [...] (Paragone: f. $5 \mathrm{v}$ ) $[\ldots]$ con due, $\mathrm{tt}$, ne ho trovate scritte alcune come sujetto, efetto, ma per quanto mi posso accorgere per la commune espressione di queste voci et d'infinite altre simili veccio che non pronuntiano mai le due, tt, con quella forza che facciamo noi, anzi pare che le dicano di maniera ch'alla sola pronunzia nessuno mai possa giudicare esservi se non una, t, sola (Paragone: f. 9 r) .

6 En la citas de ejemplos de Il paragone della lingua toscana et castigliana y de las Osservationi della lingua castigliana mantengo las grafías y las eventuales erratas de los originales, así como la diferenciación entre letra redonda y letra cursiva. Utilizo la negrita para evidenciar los elementos que destaco en mi exposición. 
Non conosco differenza alcuna attorno la pronuntia della lettera, d, la qual ha la medesima forza nelle nostre voci, dormire, dente, dito, et altre simili, et nelle Castigliane dormir, diente, dedo, et tutte l'altre (Paragone: f. $11 \mathrm{r}$ ).

[...] son andato pensando qual regola si potesse trovare con la qual, se non di tutte almeno della maggior parte si potesse aver notitia, dove s'habbia da scrivere questa y greca, et finalmente per quanto s'ha possuto estendere il mio ingegno, ho osservato che queste sillabe $a y, e y, o y, v y$, tanto in principio quanto in mezzo et in fine delle parole si scrivono con y greca cio è che seguendo la, $i$, dopo, a, e, o, u, ha da essere y greca come hay, haya, hayamos, pleyto, azeyte, creya, leya, ley, rey, creydo, leydo, soy, doy, voy, huyr, destruyr, muy suyo, ruyz cuyo. Et questa mi par regola generale, ancor che si trovino altre voci con la y creca fuori di questa regola come ya, yua, yr, yugo voci sopradette con altre molte che nelli buoni autori si trovano (Paragone: f. $38 \mathrm{r} / \mathrm{v}$ ).

Los ejemplos en lengua española están demarcados por una escritura redonda que se contrapone a la itálica de la explicación gramatical ${ }^{7}$, mientras que los ejemplos en italiano no se diferencian tipográficamente y quedan involucrados en la voz del autor; a veces, y especialmente si se trata de letras o de partículas de breve extensión, las muestras están delimitadas por comas, como cuando el autor registra el uso general de la vocal $e$ delante de $s$ impura y censurando la pronunciación incorrecta del latín:

[...] non dimeno l'uso generale è di aggiungervi la, e, nel modo c'ho detto anzi l'hanno tanto per proprio che molti pronuntiando simili voci latine v'aggiungono la, e, come estabat escabellum per stabat, scabellum, il che quantunque sia solo nel proferire non nello scrivere niente dimeno essorterei ciascuno che così pronuncia le voci latine a lasciar questo abuso [...] (Paragone: f. $13 \mathrm{v}$ )

Cuando los ejemplos ofrecen la posibilidad de una aproximación contrastiva, en los casos de derivación explícita del latín, o según otros criterios a veces cuestionables, están dispuestos de forma alternada en italiano y en español:

È proprijissimo à Castigliani convertir la, $\mathrm{f}$, delle voci Latine et Toscane, in, $\mathrm{h}$, come è proprio à Toscani, il ritener la, $\mathrm{f}$, delle medesime voci latine come, fico, higo, fegato, higado, ferro, hierro, Febraio, hebrero, formoso, hermoso, feccia, hez, ferita, herida, ficcar, hinchar, fervore, hervòr, figlio, hijo, faccia, haz, fava, hava, fastidio, hastio, finqui, hasta aqui, falcone, halcòn, fare, hazèr, fatto, hecho, femina, hembra, fetore, hedòr, fuggire, huyr, forno, horno, fongo, hongo, foglia, hoja, falce, hoce, forca, horca, fumo, humo, furto, hurto, fuso,

7 Por razones tipográficas, en los ejemplos citados en este artículo se ha invertido la diferenciación entre letra redonda y letra cursiva. 
huso, filo, hilo, et mill'altre nelle quali tutte la, h ha gran spirito et gran forza per che si pone in luogo di consonante (Paragone: f. $20 \mathrm{v}$ )

Non dimeno si trovano ancor alcuni nomi che à Toscani sono del maschio et à Castigliani della femina, come, il disordine la desorden, l'ordine, la orden, il ponte, la puente, il colore la colòr, il costume, la costumbre, il ginocchio, la rodilla, il capo, la cabeça, l'alloggiamento, la posada, il miele, la miel, il letto, la cama, il latte, la leche, il sangue, la sangre, il segnale, la señal, il mare la mar [...] (Paragone: f. 49 r)

En las secciones dedicadas a los pronombres y a los verbos, los ejemplos en español y en italiano mantienen cierta extensión y, aunque se encuentren mezclados y sean difíciles de identificar con precisión, se los reconoce como fragmentos de textos escritos y extraídos de cartas, textos religiosos o documentos de diversa índole:

Nel numero dei più si terminano in $o s, \mathrm{~m}$, in $a s, \mathrm{f}$. he querido traheros todos estos exemplos, à estas leyes han de obedecer los que son naturales del reyno (Paragone: f. $74 \mathrm{v}, 75 \mathrm{r}$ ).

Mi pare che alcuna volta si truovi esto, per aquesto, las cosas que haze la divina providentia son tan iustas que dado caso que nosotros no las podamos alcançar, no por ello carecen de razón (Paragone: f. 75r).

Questa voce, glie, s'usa in luogo di lui, lei, loro in $3^{\circ}$ caso per tutti i generi et numeri, adimandandomi il Signor Duca in mio Homero subbito glie lo portai, adimandandomi i miei cavalli glie li mandai, desiderando quelli capitani le mie armi glie le offersi, volendo quelle signore la parte loro de la caccia glie la diedi. (Paragone: f. 85 r)

La búsqueda de eventuales orígenes literarios de los ejemplos más extensos ha revelado como fuente importante de muestras lingüísticas las Epístolas Familiares de Antonio de Guevara para el español y, para el italiano, el Decameron de Giovanni Boccaccio. Alessandri mezcla fragmentos de textos en total libertad, creando ejemplos extensos del todo faltos de coherencia. En un caso la voz del autor introduce y explica la muestra, como ocurre con la anécdota sobre el rey Alfonso extraída del texto de Guevara:

Para daros el parabièn en este vuestro tàn gran mal, soys pequeño, y teneys este animo tan generoso, a esta ciudàd adoos tienen preso no viene ningun en todo el año, ad alcuni che lodavano molti luoghi disse il re Alfonso, yo apruevo sèr esto todo bueno, màs yo màs querria para mi hallarme en carrioncillo (Paragone: f. 75v).
Cuando el buen rey don Alonso estaba en Nápoles rodeado de muchos príncipes, y le loaban la generosidad de Roma, la grandeza de Venecia, la riqueza de Florencia y la opulencia de Milán, respondía él: «Loo y apruebo ser eso todo bueno; mas yo para mí más querría hallarme en Carrioncillo». (Epistola XLI) 
En el ejemplo que se reproduce a continuación se puede apreciar el procedimiento que Alessandri adopta al extraer ejemplos de textos extensos, y marcadamente literarios. Se trata de la simple yuxtaposición de muestras ad hoc rastreadas en distintos lugares del texto, eventualmente con leves modificaciones, glosas («lo per ello») o sustituciones («el qual voto» por "prometióles de les hacer haber las hermosas mujeres de Roma para sus deleites»). La última parte "aunque le dio Mercurio este consejo, el de imprudente no lo quiso tomàr» tal vez esté extraída de la Odisea, de la que en otros lugares tenemos referencias más reconocibles: «dime aquèl varón suave musa" (Paragone: f. 77r), "Telemaco tan bien subiò à un aposento muy rico» (Paragone: f. 2v).

Comparando los ejemplos en italiano también podemos conocer el procedimiento adoptado por Alessandri que, evidentemente, va buscando a lo largo del Decameron las muestras lingüísticas con una finalidad exclusivamente utilitarista. A continuación se ponen en evidencia los fragmentos utilizados por el autor que pertenecen a distintas novelle del Decameron:

Dissi di sopra, chi, servire a tutti casi; et è vero che negli obliqui si truova alcuna volta usato, ma il primo caso è il suo proprio, et negli obliqui ha cui nell'uno et nell'altro numero per lo. $\mathrm{m}$. et per la $\mathrm{f}$. et nel $3^{\circ}$ caso si dice à cui et cui con la particella à, et senza essa, onde fosti et cui figliuolo, cui lasciare potesse sofficiente a riscuotere suoi crediti, cui egli per veduta non conosceva, a cui Guglielmo prestamente disse.
La qual voce Pietro udendo, subitamente levò il capo. Al quale Fineo in erminio parlando disse:

- Onde fosti ? E cui figliuolo? (Novella VII)

[...] Musciatto Franzesi [...] pensò quegli commettere a più persone; e a tutti trovò modo; fuor solamente in dubbio gli rimase cui lasciar potesse sofficiente a riscuoter suoi crediti fatti a più borgognoni. (Novella I)

L'abate fece aprir la camera per venire nella sala, e venendo si guardò innanzi, e per ventura il primo uomo che agli occhi gli corse fu Primasso, il quale assai male era in arnese e cui egli per veduta non conoscea; e come veduto l'ebbe, incontanente gli corse nello animo un pensier cattivo [...] (Novella VII)

Messere Ermino disse:

- Deh, io ve ne priego, ditemi quale è dessa;

- non aspettando lui quello dover rispondere che rispose.

A cui Guiglielmo allora prestamente disse:

- Fateci dipignere la Cortesia. (Novella VIII)

En las Osservationi della lingua castigliana los ejemplos están a menudo introducidos por el autor con las expresiones «come» «come in» «si come 
dicessimo in Spagnuolo» «in Toscano» «come dir» «come in Toscano si direbbe»; casi todas las palabras van con su traducción, o bien con su definición. Como en el Paragone, los ejemplos en español van marcados tipográficamente:

[...] ma ne sono certi nomi, ne i quali ancoa che venne l'u, con l'e, si proferisce l'u, i quali sono, aguelo; che vol dire avo; cigueña, che vol dir cicogna; aguar, verbo, che vol dir acquare, aguero, augurio; verguença, vergogna; Siguenza, ch'è una città di Spagna [...] (Osservationi: 5$)$

Miranda también utiliza otro recurso tipográfico al disponer las voces independientes de manera sinóptica («a dirimpetto»), en dos columnas separadas, para facilitar que se puedan copiar y memorizar ${ }^{8}$ :

$\begin{array}{ll}\text { el açada } & \text { la zapa } \\ \text { el abeja } & \text { l'ape } \\ \text { el adarga } & \text { la targa } \\ \text { el aguja } & \text { l'ago } \\ \text { el agua } & \text { l'acqua } \\ \text { el ala } & \text { l'ala } \\ \text { el ama } & \text { la baila } \\ \text { el anima } & \text { l'anima } \\ \text { el aparencia } & \text { l'apparenza } \\ \text { el arca } & \text { l'arca } \\ \text { el asa } & \text { il manico di caldaro, o d'altra cosa } \\ \text { el ayuda } & \text { l'aiuto (Osservationi: } 16)\end{array}$

El aparato ejemplar de las Osservationi ofrece una cantidad imponente de material lingüístico, tan abundante que se ha dicho estar a punto de romper las fronteras de lo gramatical para entrar en lo lexicográfico (Ramajo Caño 1987: 39). Miranda es consciente de tal copiosidad, y reiteradamente la anuncia, o bien la justifica, o bien declara haberse limitado en su exposición:

[...] ho messo tanti nomi per essempio; acciocché possano ancora servire alla copia delle parole, et così li ho messi per alfabeto. (Osservationi: 29)

$[\ldots]$ et in questi essempi sarò un poco lungo [...] (Osservationi: 37 )

Potria ancor'io aggiungere altri essempi; ma parendomi che questi per hora bastano, et anco per non esser notato di troppo lungo, et prolisso, darò fine, et a gli essempi, et ancora a detti pronomi, lasciando il resto all'uso [...] (Osservationi: 113)

8 Según Carreras (2002: 18) «Miranda trabajaba con listas a las que recurría a menudo para ilustrar los distintos aspectos gramaticales a medida que le hacían falta ejemplos». 
[...] et darò alcuni essempi, accioche piu facilmente si possa intendere. (Osservationi: 114)

[...] ma perche potrebbe esser difficile ad intender senza essempi, essendo cosa tanto importante alla nostra lingua, darò alcuni essempi; accioche meglio si possa intendere. (Osservationi: 130-131)

Et accioche meglio s'intenda quel che ho detto, darò alcuni essempi [...] (Osservationi: 141 )

Et accioche sia piu chiaro quel che dico, darò essempio di questi per non confondere ogni cosa. (Osservationi: 245)

El autor invita a los lectores a profundizar en sus estudios y a aprovechar las ocasiones para mejorar sus destrezas orales y escritas:

Et avvertirete ben questo, percioche si trova ne i libri spesse volte [...] (Osservationi: 113)

In quanto appartiene alla costruttione non accaderà darne molte regole percioche la esperientia e'l leggere d'i libri ve lo mostrerà. (Osservationi: 223)

E cosi molte altre cose; che si potriano a notare, le quali ascio per un esser prolisso, a chi vorrà leggere i libri [...] (Osservationi: 230)

Et per haver detto di tutte le parole che non si variano al mio parere a bastanza, porrò fine, lasciando il resto a chi vorrà affaticarsi a leggere i libri. (Osservationi: 288)

En el límite con las obras lexicográficas se sitúan especialmente las traducciones y las definiciones y explicaciones de las voces que no tienen equivalencia directa en italiano (Esteba Ramos 2007: 101):

El, cahiz, è una certa misura di Spagna, che fa quattro sacchi di quattro stara l'uno, di modo che una misura d'un, cahiz, è una misura di sedici stara di formento, o grano qual si voglia.

El, capuz, è una vesta che s'usa serrata da tutte due le bande, e arriva infino a terra, et è aperta solamente per il collo, fin'a una spanna poco più, per la qual parte si veste, et poi si serra co i bottoni.

El, albornoz, è una vesta da Cavaliero, alla Moresca, che serve per feltro, quando piove, et è d'una certa tela, come mocaiaro di colore morello, et è grande, e lunga, con certi fili lunghi che descendono per ogni parte. (Osservationi: $46-47$ )

Con respecto al italiano Alessandri, es evidente la mayor competencia comunicativa y el quehacer lingüístico de Miranda, quien sabe contextualizar y especificar el uso de los ejemplos españoles sin apoyarse en textos escritos, sino tan sólo en su propia experiencia de hablante: 
Queste due parole $a x o x$, s'usano ancora; la prima quando uno si scota, che dice ax que quema, e quell'altra si dice per dar ad intendere che non vuole quella cosa, et ancora si dice alle galline, ox oxe per pararli via, et si dice, oxe a fuera, cioè non lo voglio fare. (Osservationi: 278)

Queste due particelle, embalde, debalde sono molto diverse nella significatione, percioche embalde, significa indarno, come embalde ostrabajays cioe indarno v'affaticate; debalde però significa di gratia cioè senza pagamento et alcuna volta significa a buon prezzo, ma all'hora s'usa un'altra particella che è barato che significa veramente quello. (Osservationi: 280)

Esta misma elevada competencia comunicativa es la que le permite elaborar ejemplos ad hoc, caso en el que se podría identificar un metaanimador de discursos imaginados y atribuidos a personajes de ficción:

No está en casa? Nò, pues donde està ? esta en la plaça, mas presto estarà en casa.

A ora se leerà, $y$ despues se cantarà, que a un no se ha cantado; e cantar se ha oy? si $y$ despues que se havrà cantado, y leydo, se yrà a comer.

Diosea conmigo

Vino Pedro con tigo?

Si comigo vino, y traya consigo otros tres.
Non è in casa? no, adunque dove è ? è in piazza, ma presto sarà in casa. (Osservationi: 142)

Hora si leggerà, et poi si canterà, che ancora non s'è cantato, si canta hoggi? Si: et doppo haversi cantato, e letto s'anderà a desinare. (Osservationi: 176)

Dio sia meco, Venne Pietro teco?

Si meco venne, et menava seco altri tre.

(Osservationi: 98 )

A la hora de utilizar fuentes literarias, el procedimiento adoptado por Miranda es el mismo que el de Alessandri: se extraen fragmentos de las obras consultadas, adaptándolos y modificándolos según la necesidad de la explicación gramatical. El texto de referencia es la Thebayda, comedia urbana publicada en Valencia en 1521, junto con la Comedia Serafina ${ }^{9}$, de la que también se reconoce un fragmento. A continuación se cotejan algunos ejemplos con las fuentes, omitiendo la traducción al italiano que el autor propone en columnas paralelas:

9 Los dos únicos ejemplares conocidos de estas obras se encuentran en el Museo Británico y en la biblioteca de Harvard; se trata de una edición que contiene junto con la Thebaida y la Serafina también la comedia Hipólita (Carrasco 1994: 1991) 
Sobre dezir Platon que la prudencia, era guia de las virtudes; y sobre dezir Socrates su maestro que toda virtud sin la prudencia no era nada; a osadas que entre un millon de hombres no halleys uno prudente.

Sobre haber gastado con el mi hazienda agora no me quiere ver.

Sobre haver comido mil vezes juntos, dize que nunca me viò (Osservationi: 284)

Vengo tan cargado de buenas, nuevas, como el abeja viene a la colmena en el tiempo de mucha flor;

vengo tan contento como Roldan en ganar su espada,

huelgo tanto de verte como si huviera dos años que no te hubiera visto? tan desseada era de mi tu venida, como era del grande Alexandro la respuesta del Dios Amon

su venida sea con tanta prosperidad como fue la del furio Camillo a los Romanos. (Osservationi: 294-295)

\section{AMINTHAS}

Cierto es, como refiere el Cicerón en una epístola, ser dicho del Eusebio, que la virtud no se alcance al hombre lleno de felicidad, y sin ella ni somos buenos ni podemos hacer buenas cosas. Pues cuan despojados estamos de esta perfectísima y santa virtud, ya lo veis; claro está, harto ciego es como dicen, el que no ve por tela de cedazo; ¿y qué queréis más? salvo que entre un millón de hombres no veréis uno prudente; sobre decir Platón que la prudencia era guia de las virtudes, y sobre decir Sócrates, su maestro, que toda virtud sin la prudencia era ninguna cosa; y no sin causa á osadas se lee en la vida de Diógenes, aquél tan extremado en los virtuosos actos, que un dia comenzó á decir á voces : hombres, hombres, venid [...]. (Thebayda, 329-330)

\section{GALTERIO}

Veturia entra alegre según que en el gesto lo muestra, y arriba sube; voy á ver lo que quiere, que cierto no es sin gran misterio, y tan cargada viene de buenas nuevas como la abeja viene á la colmena en el tiempo de mucha flor (Thebayda, 505).

[...] y con medio rucio quedó tan contenta, como Roldan en ganar su espada [... (Thebayda, 351).

[...] y de cierto me puedes creer que me huelgo tanto de verte, como si hubiera dos años que no te hubiera visto; $y$ tan deseada era de mí tu venida, como era del gran Alejandre la respuesta del dios Amon, al tiempo que fué á se informar y saber sus sucesos [...] (Thebayda, 96).

\section{FRANQUILA}

Siéntate, Galterio, y tu venida sea con tanta prosperidad y tan en buen hora como fué la de Furio Camilo á los romanos, cuando elegido dictador, alzado su destierro, vino á remediar el Capitolio (Thebayda, 70-71). 
Antes los dos polos se mudaran de su costumbre, y antes el planeta mercurio dexarà de ser convertible, y antes la otava esfera dejarà caer las estrellas fixas que yo en un minuto haga mudança de lo prometido, Antes la natura del cielo dexarà de estar templada con aguas $y$ antes los elementos inferiores se encenderan con la confragracion del fuego superior, que en mi haya un punto de inconstancia.

$Y$ antes el hijo de Latona dexarà si lumbre a costumbrada, queyo dexe de seguir tu voluntad.

Antes se olvidarà la noble Diana de dar claridad, a las tinieblas nocturnas.

$Y$ antes el quarto planeta se olvidarà de dar bueltas en el zodiaco, que a mi me passe por pensamiento olvidarte. (Osservationi: 316-317)
[...] en lo demás que Veturia dices, antes los dos polos se mudarán de su costumbre, y antes la octava esfera dejará caer las estrellas fijas, que yo en un minuto haga mudanza de lo prometido; y antes el planeta Mercurio dejará de ser convertible, que en mi haya un punto de inconstancia; $y$ antes el huerto de los deleites dejará de estar supósito al signo de Aries y Libra, y se apartará de la vecindad de la tórrida zona; y de la cara de Apolo antes dejará de pasar el centro del dobladas veces en el año, que á mi me pase por pensamiento de enojar á mi señora; y antes la natura del cielo dejará de estar templada con aguas; y antes los elementos inferiores se encenderán con la conflagración del superior fuego, que yo deje de servir á Cantaflua; burla, burla otras burlas, amiga Veturia, y juega otros juegos, y en burlas. (Thebayda, 511-512).

\section{GALTERIO}

Pues, descanso mio, ¿qué quieres que hagamos? Que antes el hijo de Latona, dejará su lumbre acostumbrada, que yo deje de seguir tu voluntad. (Thebayda, 87).

EVANDRO.- ¿Olvidar dizes, Popilia? Antes se olvidará la noble Diana de dar claridad a las [tinieblas] noturnas, y antes los polos se olvidarán de ser guía de los errados mareantes, $y$ antes el cuarto planeta se olvidará de dar la buelta en el zodíaco que a mí me pase por pensamiento olvidar a mi señora Serafina. (La comedia Serafina: 16)

Los fragmentos más extensos extraídos de la Thebayda se encuentran en el tercer libro y se utilizan para ejemplificar los modos metafóricos, las exclamaciones y las invocaciones, es decir, los procedimientos retóricos más elaborados y menos frecuentes en la oralidad. Por otro lado, el uso de textos teatrales proporciona una dimensión dialógica que puede fácilmente mezclarse con otras fuentes, posiblemente de origen no literario: 
O como te huelgas con la soledad, pues para ser Diogenes philosopho era mucho.

Que hazes? para ser loco era mucho esto Esto no entendeis; pues para no haver estudiado era mucho,

Que pensais que soy juvenal que tengo de dividir mi razonamiento en satiras?

\section{AMINTHAS}

¡Oh, cómo te huelgas de la soledad y de no conversar con nadie! Pues para ser Diógenes aquél tan extremado entre todos los antiguos filósofos, seria mucho (Thebayda, 247).

\section{FRANQUILA}

¿Cómo á qué fin? ¿Y piensas que soy el Juvenal, que tengo de ir dividiendo mi razonamiento en sátiras? Acabado he, y si me has querido entender por gentil estilo te lo he dicho (Thebayda, 294).

Pensais ques la fabula de Orestes que estaba escrita en los libros, en las margines, $y$ en las cubiertas, y aun no estaba acabada? (Osservationi: 297-298)
[...] y por aquí te dirá una retartadilla más larga que la fábula de Orestes, de la que dice el Juvenal que estaba escrita en el libro y en las márgenes y en las coberturas, y que aún no estabaacabada, yesverdad [...] (Thebayda,233).

Si Alessandri en Il paragone della lingua toscana et castigliana recurre a la literatura, a las «buenas impresiones » para extraer ejemplos y compensar su limitado conocimiento lingüístico (Quijada Van den Berghe 2008: 644), también Miranda, cuya competencia lingüística es incuestionable, entiende los textos literarios como una importante fuente de información, sobre todo para aportar ejemplos ilustrativos de cierta elaboración retórica. Con respecto a los textos artísticos obtenidos mediante la escritura, en prosa o en poesía, los microtextos ejemplares, cualquiera que sea su origen, pertenecen a un ámbito artesanal cuya finalidad utilitarista se explicita ya desde el principio: la enseñanza de la lengua extranjera. Los fragmentos narrativos no son ejemplares por su contenido, sino que son instrumentales en la enseñanza lingüística; el pacto comunicativo que el emisor establece con el destinatario vincula el paradigma a la dimensión metalingüística únicamente. Alessandri y Miranda no pretenden suministrar al lector unas lecturas recomendadas para su formación intelectual o moral, y por eso no nombran ninguna obra literaria de referencia. En las primeras gramáticas de español para italianos el aparato ejemplar de derivación literaria se estructura como un repertorio de textos y esquemas cuya utilidad y finalidad es exclusivamente metalingüística, prescindiendo de los contenidos narrados y de la calidad artística de los textos fuente. 


\section{Referencias bibliográficas}

Fuentes primarias

Alessandri d'Urbino, Giovanni Mario, 1560, Il paragone della lingua Toscana et Castigliana, Napoli, Mattia Cancer.

Boccaccio, Giovanni, 1951-1952 [1349/1351], Decameron, ed. de V. Branca, correcciones de N. Sapegno, Firenze, Le Monnier, edición electrónica

http ://culturitalia.uibk.ac.at/hypercorpus/b/boccaccio/decameron/DECAMERO0. htm $(23 / 12 / 2009)$.

Comedia llamada Thebayda, 1871 [1520/1521], en Coleccion de libros españoles raros ó curiosos, vol. 22, Madrid, Rivadeneyra, http://www.archive.org/details/ colecciondelibro22almauoft (23/12/2009).

Guevara, Antonio de, 1886 [1539/1541], Epistolas familiares y escogidas, Barcelona, Biblioteca Clásica Española, http://www.archive.org/details/epistolas familia00guevuoft (23/12/2009).

Guevara, Antonio de, 2000 [1539 / 1541], Libro primero de las epístolas familiares, edición digital, Alicante, Biblioteca Virtual Miguel de Cervantes, http://www. cervantesvirtual.com/servlet/SirveObras/06923852199547262977857/index.htm (23/12/2009).

La comedia Serafina, 2003 [1521], ed. de J.L. Canet, Anexos de la Revista Lemir, http://parnaseo.uv.es/Lemir/Textos/Serafina/Serafina.pdf (23/12/2009).

Miranda, Giovanni, 1566, Osservationi della lingua Castigliana divise in quattro libri, Vinegia, Gabriel Giolito de' Ferrari.

Nebrija, Antonio de, 1989 [1492], Gramática de la lengua castellana, ed. de A. Quilis, Madrid, Centro de Estudios Ramón Areces.

Valdés, Juan de, 1982 [1533], Diálogo de la lengua, ed. de J.M. Lope Blanch, Madrid, Castalia.

Fuentes secundarias

Bertini, Giovanni Maria, 1953, "Della prima grammatica italo-spagnola», in: Estudios dedicados a Menéndez Pidal, Madrid, C.S.I.C., IV : 27-35.

Carrasco, Félix, 1994, "La Thebaida versus La Celestina: perspectivas ideológicas», in F.B. Pedraza Jiménez, R. González Canal, (eds.), Los albores del teatro español, Actas de las XVII Jornadas de teatro clásico, Almagro, julio de 1994, Ciudad Real, Festival de Almagro - Universidad de Castilla La Mancha: 191-203, http ://www.uclm.es/organos/Vic_Investigacion/centros/ialmagro/ publicaciones/pdf/CorralComedias/5_1994/14.pdf (23/12/2009).

Carreras i Goicoechea, Maria, 1993, «Algunos datos bio-bibliográficos sobre Giovanni Miranda», Anuari de Filologia de la Universitat de Barcelona, XVI, sèrie $F, 4: 9-24$.

Carreras i Goicoechea, Maria, 2002, «El papel de las Osservationi della lingua castigliana de Giovanni Miranda (1566) en la historia de la enseñanza del español para italianos », Quaderni del CIRSIL - 1: 9-23. 
Chevillard, Jean-Luc, Colombat, Bernard, Fournier, Jean-Marie, Guillaume, Jean-Patrick, Lallot, Jean (eds.), 2007 «L'exemple dans quelques traditions grammaticales (formes, fonctionnement, types)», Langages, 168: 5-31.

Chierichetti Luisa, 1997, "Grammatiche cinquecentesche di spagnolo per italiani: Il paragone della lingua toscana et castigliana di Giovanni Mario Alessandri e le Osservationi della lingua castigliana di Giovanni Miranda», in: Chierichetti L., Lenarduzzi, R., Uribe Mallarino, M., Spagnolo/Italiano:Riflessioni interlinguistiche, Milano, Cuem: 5-38.

Croce Alda, 1971, "Relazioni della letteratura italiana con la letteratura spagnola», in: A. Viscardi et al. (eds) Letterature comparate, Milano, Marzorati: 101-144.

Croce, Benedetto, 1949, La Spagna nella vita italiana durante la Rinascenza, Bari, Laterza.

Esteba Ramos, Diana, 2005, Los ejemplos en las gramáticas del español como lengua extranjera: Siglo de Oro (tesis doctoral), Málaga, Universidad de Málaga.

Esteba Ramos, Diana, 2007, «Una visión del mundo hispánico contenida en los ejemplos de las gramáticas del Español como lengua extranjera en el Siglo de Oro » in: Juan de Dios Luque Durán y Antonio Pamies Bertrán (eds), Interculturalidad y lenguaje, II, Granada: Granada Lingüística: 95-104.

García Dini, Encarnación, 1995, «Los Dialoghi di Massimo Troiano (Venezia, Bolognino Zaltieri, 1569) entre traducción y refundición», in: Scrittura e riscrittura. Traduzioni, refundiciones, parodie e plagi, Atti del Convegno AISPI di Roma (12-13 novembre 1993), Roma, Bulzoni: 11-21.

Goffman, Erving, 1987 [1981], «Footing», in: Forme del parlare, Bologna, Il Mulino, 1987.

Lo Cascio, Vincenzo, 1991, Grammatica dell'argomentare, Firenze, La Nuova Italia.

Mele, Eugenio, 1914, "Tra grammatici, maestri di lingua spagnola e raccoglitori di proverbi di lingua spagnola in Italia», Studi di Filologia Moderna, VII, 1-2: $13-41$.

Meregalli, Franco, 1974, Presenza della letteratura spagnola in Italia, Firenze, Sansoni.

Quijada Van den Berghe, Carmen, 2008, «Pautas para el estudio de las autoridades y el canon en las gramáticas del español del siglo XVII», in: José Jesús Gómez Asencio (dir.), El castellano y su codificación gramatical, II, León, Fundación Instituto Castellano y Leonés de la Lengua: 641-666.

Quondam Amedeo, 1978, «Nascita della grammatica. Appunti e materiali per una descrizione analitica», in: Alfabetismo e cultura scritta nella storia della società italiana, Perugia, Università degli Studi: 271-309.

Ramajo Caño, Antonio, 1987, Las gramáticas de la lengua castellana desde Nebrija a Correas, Salamanca, Ediciones Universidad de Salamanca.

Sabatini Francesco, 1990, "Analisi del linguaggio giuridico. Il testo normativo in una tipologia generale dei testi», in: Mario D’Antonio (ed.), Corso di studi superiori legislativi 1988-1989, Padova, CEDAM, 675-724. 